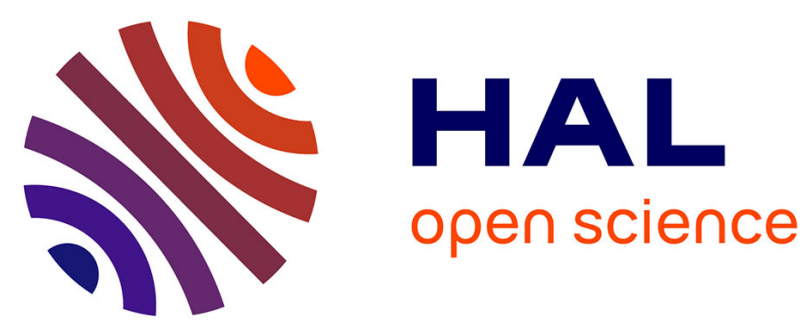

\title{
Interval arithmetic for short-circuit computation in MV radial networks with Distributed Generation
} Wendy Carolina Briceño Vicente, Raphaël Caire, Nouredine Hadjsaid

\section{To cite this version:}

Wendy Carolina Briceño Vicente, Raphaël Caire, Nouredine Hadjsaid. Interval arithmetic for shortcircuit computation in MV radial networks with Distributed Generation. Power and Energy Society General Meeting, 2012 IEEE, Jul 2012, San Diego, United States. 10.1109/PESGM.2012.6344605. hal-01809961

\section{HAL Id: hal-01809961 https://hal.science/hal-01809961}

Submitted on 8 Jun 2018

HAL is a multi-disciplinary open access archive for the deposit and dissemination of scientific research documents, whether they are published or not. The documents may come from teaching and research institutions in France or abroad, or from public or private research centers.
L'archive ouverte pluridisciplinaire HAL, est destinée au dépôt et à la diffusion de documents scientifiques de niveau recherche, publiés ou non, émanant des établissements d'enseignement et de recherche français ou étrangers, des laboratoires publics ou privés. 


\title{
Interval Arithmetic for Short-Circuit Computation in MV Radial Networks with Distributed Generation
}

\author{
W. C. Briceño Vicente Student Member IEEE, R. Caire, Member IEEE, N. Hadjsaid, Senior Member \\ IEEE
}

\begin{abstract}
The short-circuit computations are usually performed in power system studies to determine currents and voltages in the power grid under fault. The interconnection of Distributed Generation (DG) increases the short-circuit currents and may cause that electric equipments overcome their capacity limits. At the same time, the increment of renewable energy sources and other forms of DG, introduces more uncertainties to the network. This issue has motivated the development of methodologies to evaluate the effects of DG on distribution networks. The fuzzy sets theory is implemented to evaluate the impact of uncertainties (of both power generation and network parameters) on fault levels considering the IEC Standard 60909. The solution is compared to Monte-Carlo Simulation (MCS) which is the most usual simulation used to solve stochastic problems.
\end{abstract}

Index Terms - Short-circuit currents, Fault currents, Distributed power generation, Distribution functions, Fuzzy sets theory, Monte-Carlo simulation, Membership functions, Power distribution, Probability distribution, Wind power generation.

\section{NOMENCLATURE}

DFIG : Double Fed Induction Generators

DG : Distributed Generation

FN : Fuzzy Number

IA : Interval Arithmetic

LV : Low Voltage

MCS : Monte Carlo Simulation

MV : Medium Voltage

PF : Power flow

PDF : Probabilistic Density Function

PODF : Possibility Distribution Function

PPCP : Possibility-Probability Consistency Principle

RDS : Radial Distribution System

\section{INTRODUCTION}

$T^{1}$ he integration at large scale of Distributed generation (DG) into existing distribution networks represents a tremendous challenge from planning as well as operational

Manuscript received XXX. This work was supported by the G2Elab, Grenoble INP, St Martin d'Hères, BP 46, 38402; France.

W. C. Briceño Vicente, R. Caire and N. Hadjsaid are with the G2Elab, St Martin d'Hères, BP 46, 38402; France. (e-mails: wendy.bricenovicente@g2elab.grenoble-inpg.fr, nouredine.hadjsaid@g2elab.grenoble-inpg.fr,). point of views. The interconnection of DG must guarantee that all grid parameters (voltage regulations, power quality [2], fault levels, etc.) are in between the specified limits of distribution networks. In addition, the random behavior of some DG energy sources such as wind power adds new constraints to for the interconnection of these DGs into power grids.

Short-circuit currents are of the most important data in planning as well as in operational studies. Fault levels are usually obtained by the deterministic method while considering often conservative safety factors (worst case due to the limited knowledge of variable randomness involved in the calculus [9]).

In this case, fault levels are influenced by several factors. Some of them are invariant and others may vary randomly. Thus, short-circuit currents depend primarily on:

a) Network parameters such as line impedances and line lengths. Generally well-known but with some uncertainties.

b) Operational characteristics such as the network topology and the load profile which varies uniformly at any time of the year.

c) The fault type, period and location which vary randomly and depend on external disturbances and human errors.

The incorporation of randomness in fault level calculation has considerable benefits in the adoption of more realistic safety factors, which could allow better consideration of DG interconnection both in medium voltage (MV) and low voltage (LV) levels. In order to better understand and determine the margins and associated risks for DG interconnection into the power grid, a probabilistic or a possibilistic [16] approach is needed.

A first proposal of probabilistic short-circuit computation was made in Canada at the end of the 70's [6, 7] using the Monte Carlo Simulation (MCS) to deal with the difficulties of increasing fault currents which caused restrictions in the power grid. In the early 80 's Ontario Hydro encouraged the research of other techniques [10], [9], [14] and [12], to determine the probability distributions of short-circuit currents and other information needed for their project studies such as in: planning, reliability, risk analysis, etc. However, due to computation burden of MCS methods, analytical methods [8] were developed. Therefore, two methods are used in 
probabilistic short-circuit studies: analytical methods and MCS methods.

Nevertheless, the probabilistic technique is not the only way to deal and solve problems related to uncertainties. In the 60 's, the fuzzy sets theory was introduced by Lotfi Zadeh, through membership functions which model the vagueness of a set and introduced the concept of a partial truth of a variable through the degrees of membership function of its set. The fuzzy sets theory allows the conversion from a probability density function (PDF) to a possibility distribution function (PODF); and also allows mathematical operations among the fuzzy sets for every degree of membership function to the set, which is called interval arithmetic of fuzzy sets.

Interval arithmetic (IA) technique and fuzzy sets theory have been implemented before, solving the Power Flow (PF). problem in Radial Distribution Systems' (RDSs) [5]. PF algorithm in radial topologies can be reformulated in terms of basic arithmetical operations, hence IA can be implemented. Short-circuit computations are performed according to IEC Standard 60909 [3] recommendations, because of its accuracy, analytical character and no-matter which network configuration, radial or meshed.

The IEC 60909 is used primarily for networks with a nominal voltage ranging from $\mathrm{LV}$ to $\mathrm{HV}$, less than $550 \mathrm{kV}$ and its calculus implements the symmetrical-component principle.

This paper proposes to apply the IA method in three-phase short-circuit solutions considering IEC 60909 based on symmetrical-component theory. The study case is on MV distribution network [2], which contains four DG types; the results obtained by the IA method are validated and compared to the MCS solution.

\section{Probabilistic ShORT-CIRCUIT CALCUlation}

The analysis of probabilistic short-circuit has as goal, proving the probability distributions of short-circuit currents, to avoid overcome maximal network currents, electrodynamic forces or voltage sags, generators disconnection.

\section{A. Analytical method}

The analytical method is based on expressions derived from probability theory and their application to short-circuit computations. It models variable uncertainties as PDF and solves the short-circuit problem using convolution techniques, valid for the arithmetic of random variables. The analytical method was an alternative to MCS approach providing good accuracy in results and the reduction of computational cost required by MCS [1]. Nevertheless, analytical method may require numerical solutions the case of integrals without explicit solutions.

\section{B. Monte Carlo Simulation}

The MCS is a numerical approach for probabilistic shortcircuit analysis. The two main features about MCS are random number generation and random sampling [4]. This simulation obtains the PDF of short-circuit currents of an electrical system. In order to obtain a high degree of accuracy, the MCS requires large amount of short-circuit computations, which can be very time-consuming, depending on the computational equipment performances. The MCS method is unpractical for real-time simulations; however, short-term analysis such as one day ahead, is usually suitable, depending on the size of the power system.

\section{POSSIBILISTIC BACKGROUND}

Fuzzy logic is a superset of conventional (Boolean) logic that has been extended to handle the concept of partial truth of truth values between "completely true" and "completely false". It was introduced by Zadeh, as a means to model the uncertainty of natural language where human estimation is influential. Since Zadeh introduced this concept has been grasped by possibility distribution function (PODF), which is numerically equal to the membership function.

\section{A. Crisp sets}

It is a subset $U$ of a set $S$ defined as a mapping from the elements of $S$ to the elements to the set $\{0,1\}$.

$$
U: S \rightarrow\{0,1\}
$$

where the value zero is used to represent non-membership, and the value one is used to represent membership.

\section{B. Fuzzy sets}

Similarly, it is a subset $F$ of a set $S$ defined as a mapping from the elements of $S$ to the elements to the set $[0,1]$.

$$
F: S \rightarrow[0,1]
$$

where the value zero is used to represent complete nonmembership, the value one is used to represent complete membership, and values in between are used to represent intermediate degrees of membership.

The set $S$ is referred to as the universe for the fuzzy subset $F$. Frequently, the mapping is described as the membership function of $F$. In practice, the terms "membership function" and fuzzy subset get used interchangeably.

\section{Fuzzy numbers}

A fuzzy set $\tilde{A} \in \tilde{A}(\Re)$ is called a fuzzy number (F.N) satisfies the following conditions:

(a) $\widetilde{A}$ is normal, that is, $\operatorname{hgt}(\widetilde{A})=1$;

(b) $\widetilde{A}$ is convex;

(c) There is $\bar{x} \in \mathfrak{R}$ with $\quad \widetilde{A}(\bar{x})=1$, that is, $\operatorname{core}(\widetilde{A})=\bar{x}$;

(d) The membership function $\tilde{A}(x), x \in \mathfrak{R}$, is at least piecewise continuous.

Based on the properties of convexity and normality of continuous fuzzy numbers, there always exists a closed interval for any $\alpha$-cuts level $\left\{x / \widetilde{A}_{\tilde{A}}(x) \geq \alpha\right\}$ of the membership function. The set collection for which membership value is at least $\alpha$ is called "interval of confidence". The fuzzy number properties, $\alpha$-cuts and their intervals are shown in the Fig. 1. 


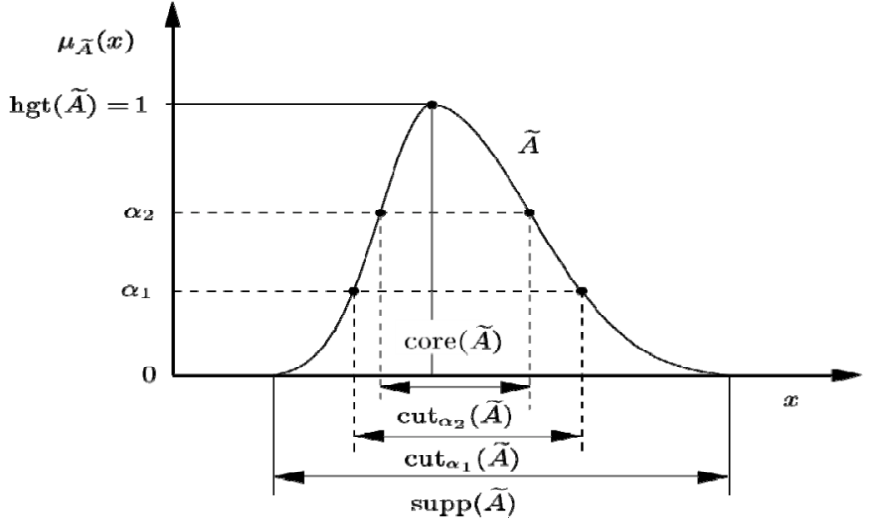

Fig. 1. Fuzzy number and membership function $A$ and $\alpha$-cuts [2].

Any fuzzy number (F.N) can be represented by a family of "interval of confidence". There are many different classes of F.Ns, but the triangular and the trapezoidal (Tr.F.N.) ones have been used extensively in most engineering applications.

\section{Trapezoidal fuzzy number}

The membership function of a triangular fuzzy number is represented by a quadruple $A=\left[a_{1}, a_{2}, a_{3}, a_{4}\right]$ and is given by the following membership function,

$$
{ }_{A}(x)= \begin{cases}0, & x<a_{1}, x>a_{4} \\ \frac{x-a_{1}}{a_{2}-a_{1}}, & a_{1} \leq x \leq a_{2} \\ 1, & a_{2} \leq x \leq a_{3} \\ \frac{-x+a_{4}}{a_{4}-a_{3}}, & a_{3} \leq x \leq a_{4}\end{cases}
$$

where $a_{1}, a_{4}$ are the extremes values for $\alpha=0, a_{2}, a_{3}$ are the extremes values for $\alpha=1$ and $a_{1} \leq a_{2} \leq a_{3} \leq a_{4}$.

It can also be interpreted in terms of confidence intervals of $\alpha$-cuts, as follows:

$$
A_{\alpha}=\left[a_{1}+\alpha\left(a_{2}-a_{1}\right), a_{4}-\alpha\left(a_{4}-a_{3}\right)\right], \quad \forall \alpha \in[0,1]
$$

A triangular fuzzy number can be interpreted as a special case of a trapezoidal fuzzy number $a_{2}=a_{3}$.

\section{E. Basic operations with $\alpha$-cuts}

Fuzzy numbers and fuzzy arithmetic approach consists in extending the usual arithmetic of crisp numbers to the intervals generated by $\alpha$-cuts of a fuzzy number [11]. The result is an interval which corresponds to the $\alpha$-cut of the input fuzzy numbers. By definition, an interval is represented by its real bounds, as follows:

$$
a=\lfloor\underline{a}, \bar{a}]=\{a \in \mathfrak{R} / \underline{a} \leq a \leq \bar{a}\}
$$

where $\underline{a}$ is the minimum and $\bar{a}$ is the maximum of $a$. Any real number is substitute with its interval.

The four basic arithmetical operations $(+,-, \times, \quad)$ among fuzzy intervals derived from $\alpha$-cuts [11] are pointed out here. If $a$ and $b$ are two real intervals:

$$
\begin{aligned}
& {[\underline{a}, \bar{a}\rfloor+[\underline{b}, \bar{b}]=[\underline{a}+\underline{b}, \bar{a}+\bar{b}]} \\
& {[\underline{a}, \bar{a}]-[\underline{b}, \bar{b}]=[\underline{a}-\bar{b}, \bar{a}-\underline{b}]}
\end{aligned}
$$

$[\underline{a}, \bar{a}] \times[\underline{b}, \bar{b}]=\left[\begin{array}{l}\min (\underline{a} \times \underline{b}, \underline{a} \times \bar{b}, \bar{a} \times \underline{b}, \underline{a} \times \underline{b}), \\ \max (\underline{a} \times \underline{b}, \underline{a} \times \bar{b}, \bar{a} \times \underline{b}, \underline{a} \times \underline{b})\end{array}\right]$

$\lfloor\underline{a}, \bar{a}\rfloor\lfloor\underline{b}, \bar{b}\rfloor=\lfloor\underline{a}, \bar{a}\rfloor \times(1 \quad\lfloor\underline{b}, \bar{b}])$ if $0 \notin\lfloor\underline{b}, \bar{b}\rfloor$

$1[\underline{b}, \bar{b}]=[\min (1 \quad \underline{b}, 1 \quad \bar{b}), \max (1 \quad \underline{b}, 1 \quad \bar{b})]$ if $0 \notin[\underline{b}, \bar{b}]$

where $\underline{a}$ and $\underline{b}$ are the minimums and $\bar{a}$ and $\underline{b}$ are the maximum of $a$ and $b$ fuzzy intervals.

Arithmetical operations described above are also applied to complex fuzzy numbers. In this case, complex fuzzy numbers must satisfy all conditions of section IV subsection $\mathrm{C}$ in its real and imaginary parts.

\section{F. The Possibility-Probability Consistency Principle}

The Possibility-Probability Consistency Principle (PPCP) was first proposed by Zadeh [16] to achieve a compromise between the possibility and probability information. The PPCP transforms a probability density function (PDF) into its corresponding possibility distribution function (PODF) with a specified consistent degree consistently as shown below:

$\min \frac{1}{2} \int_{-\infty}^{+\infty} 2(x) d x$

such that

$$
C-\int_{-\infty}^{+\infty} p(x)(x) d x \leq 0, \quad 0 \leq \quad(x) \leq 1
$$

where $\mu(x)$ can be considered as the derived mean PODF, $p(x)$ can be considered as the derived mean PDF and $C$ shows the consistency degree of this transformation and the possibility of the real mean value being located within the mean interval defined by PODF.

\section{DISTRIBUTION NETWORKS SHORT CIRCUIT}

The short-circuit current is usually considered as the sum of a symmetrical component (ac) and an aperiodic (dc) decaying component. Maximum and minimum values of the short-circuit currents are considered, for both balanced and unbalanced faults and depend on network impedances and correction factors [2].

\section{A. Short-circuit impedances}

The computation of short-circuit currents needs network component impedances such as: upstream network $\left(\underline{Z}_{Q}\right)$, overhead lines and cables $\left(\underline{Z}_{L}\right)$, transformers with or without on-load tap-changer $\left(\underline{Z}_{T}\right)$, synchronous generators $\left(\underline{Z}_{G}\right)$, induction motors $\left(\underline{Z}_{M}\right)$, unit transformers $\left(\underline{Z}_{S}\right)$; impedances of reversible static converter-fed drives can be treated as induction motors. Impedances of any other static converter, shunt capacitor or non-rotating load is ignored in the shortcircuit calculus.

\section{B. Correction factors}

In order to compensate the various simplifying assumptions of impedances, IEC 60909 introduces impedance correction factors for transformers $\left(K_{T}\right)$, synchronous generators $\left(K_{G}\right)$, power station $\left(K_{S}\right)$ and unit transformers 
$\left(K_{S O}\right)$, those factors are multiplied by their respective impedances in the short-circuit computation.

\section{FAULT LEVEL CALCULATION IN NETWORKS WITH DG}

Based on the type of generator or power converter used, four main types of DG units are distinguished in short-circuit current contributions. The models are extension of the IEC 60909 methodology, not included in the Standard.

A. Type I: synchronous generators directly coupled to the grid (e.g. Small Hydroelectric Plants, Combined Heat and Power Plants)

If synchronous generators are connected directly to the grid, the generator impedance $\left(\underline{Z}_{G}\right)$ and the correction factor $\left(K_{G}\right)$ are applied. If the generator is connected through a unit transformer, the impedance $\left(\underline{Z}_{S}\right)$ and the correction factor $\left(K_{S O}\right)$ are applied.

$$
\begin{aligned}
\underline{Z}_{G} & =R_{G}+j X_{d}^{\prime \prime} \\
R_{G} & = \begin{cases}0.07 X_{d}^{\prime \prime}, & \text { if } V_{n}<1 k V \\
0.15 X_{d}^{\prime \prime}, & \text { if } V_{n}>1 k V\end{cases} \\
\underline{Z}_{S} & =t_{r}{ }^{2} \underline{Z}_{G}+\underline{Z}_{T H V}
\end{aligned}
$$

where $R_{G}$ is the generator resistance, $X_{d}^{\prime \prime}$ is the generator subtransient reactance and tr is the rated transformer ratio of the unit transformer.

B. Type II: Induction generators directly coupled to the grid (e.g. constant speed Wind Turbines, Small Hydroelectric Plant)

Standard IEC 60909 treats only induction motors, for which parameter values are also provided; the computation principle applied to induction motors is identical and can be used as well. The generator impedance $\left(\underline{Z}_{M}\right)$ is essentially the locked-rotor impedance of the machine.

$$
\begin{aligned}
& \underline{Z}_{M}=R_{M}+j X_{M} \\
& \underline{Z}_{M}=\frac{1}{I_{L R} / I_{r M}} \cdot \frac{U_{r M}}{\sqrt{3} I_{r M}}=\frac{1}{I_{L R} / I_{r M}} \cdot \frac{U_{r M}{ }^{2}}{S_{r M}}
\end{aligned}
$$

where $U_{r M}, I_{r M}$ and $S_{r M}$ are the machine rated voltage current and apparent power, $I_{L R} / I_{r M}$ is the ratio of lockedrotor to rated current of the machine. The ratio $R_{M} / X_{M}$ is evaluated from equivalent circuit data. Typical values are also available depending on the rated power and voltage of the motor.

C. Type III: Doubly Fed Induction Generators (DFIG), with power converters in the rotor circuit (variable speed Wind Turbines)

The DFIG can be approximated as a conventional induction generator (Type II) when calculating their maximum fault current contribution. This is due to the fact that the behavior of the machine until its disconnection from the grid is identical to a conventional induction generator.

According to the design of one manufacturer [15], the stator of the machine can be disconnected in a few cycles after the fault (30-50 ms according to Ref. [15]), while the rotor converter remains in operation to keep the generator magnetized.

D. Type IV: power converter interfaced units, with or without a rotating generator (e.g. variable speed Wind Turbines,

Photovoltaic, Gas Fueled Microturbines)

Sources interfaced to the network via a dc/ac grid-side converter by fast current controllers limit overcurrent capability. Generally overcurrent does not exceeding $200 \%$ of the rated current, without aperiodic or time-decaying components their fault current contribution is:

$$
I_{k}{ }^{\prime \prime}=k I_{r G} \text { over interval } \Delta t
$$

where $I_{r G}$ is the rated current of power interface, $k=1.5$ 2.0, $I_{k}$ " is the contribution of short-circuit current contribution and $\Delta t$ is the duration of the contribution (100 ms may be adopted here as well).

\section{CASE STUdY}

The case study is $20 \mathrm{kV}$ distribution network presented in the Fig. 2, which includes all four DG types. Data for the network and the DG units are given in [2]. The network is fed by a 150/21 kV, $50 \mathrm{MVA}$ transformer, short circuit capacity at $150 \mathrm{kV}$ side is $3000 \mathrm{MVA}$ with an impedance $R / Z=0.1$. Its maximum load is $35 \mathrm{MVA}$, at 0.85 lagging power factor. There are three wind farms and one small hydroelectric plant connected to the substation bus bars via direct MV lines. A current limiting reactor is installed at the output of Wind Farm 3. The total capacity of all DG units is 17.16 MW.

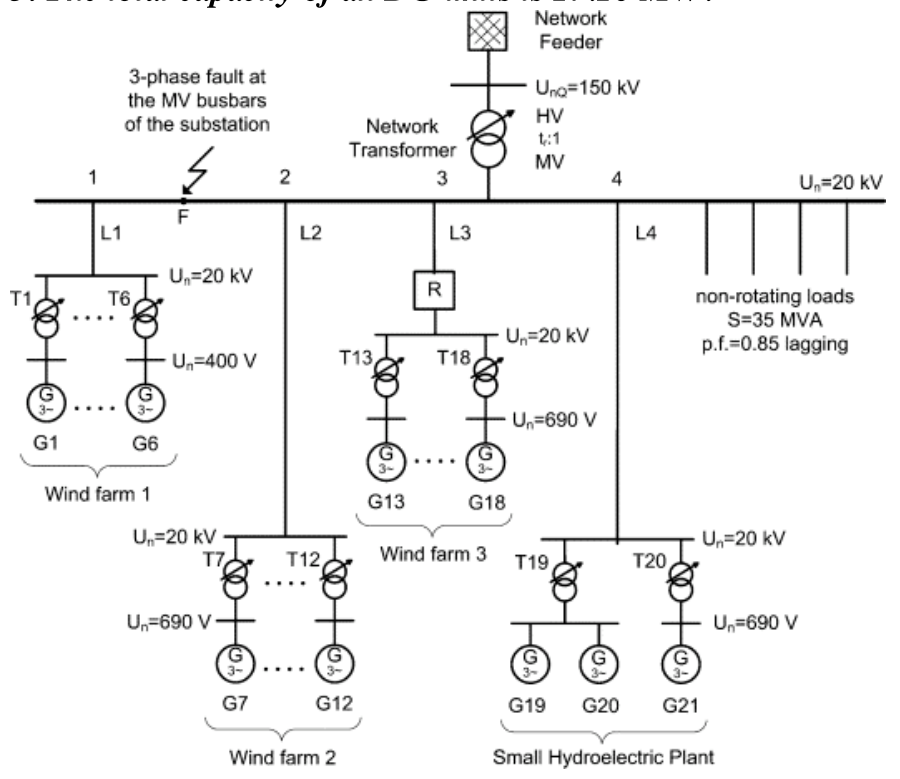

Fig. 2. Study case MV distribution network [2]

Parameters' uncertainties that are taken into account were network impedances and pre-fault sources values, considering the transformation from probability and possibilistic uncertainties (PPCP), to establish a comparison between the MCS and FN arithmetic.

$\infty$ In MCS the parameters of uncertainty were modeled as normal distribution, characterized by mean value and standard deviation $(\sigma)$. 
$\infty$ In FN the parameters of uncertainty were modeled as trapezoidal $\mathrm{FN}$, characterized by quadruple $\left(a_{1}, a_{2}, a_{3}, a_{4}\right)$.

The parameters of uncertainty considered were: line parameters that vary according to length and temperature variations; internal DG machine impedances, in both cases with a conservation variation of $5 \%$ and pre-fault voltage and current sources, which depend on transformer tap for DG and network feeder usually of $( \pm 2.5 \%$ and $\pm 5 \%)$.

Variations were taken considering the mean value $(\mu)$ of a normal distribution for each parameter of uncertainty as shown in table I.

TABLE I

PARAMETERS OF UNCERTAINTY

\begin{tabular}{|c|c|c|c|}
\hline \multirow{3}{*}{ Mncertainties } & MCS & \multicolumn{2}{|c|}{ IA } \\
\cline { 2 - 4 } & $\sigma(\%)$ & $a_{14}(\%)$ & $a_{23}(\%)$ \\
\hline Resistances & $\mu_{R}{ }^{*} 5 \%$ & $\mu_{R}{ }^{*} 7 \%$ & $\mu_{R}{ }^{*} 1 \%$ \\
\hline Reactance & $\mu_{X}{ }^{*} 5 \%$ & $\mu_{X}{ }^{*} 7 \%$ & $\mu_{X}{ }^{*} 1 \%$ \\
\hline Pre-fault voltage & $\mu_{V}{ }^{*} 5 \%$ & $\mu_{V}{ }^{*} 7 \%$ & $\mu_{V}{ }^{*} 1 \%$ \\
\hline Pre-fault current & $\mu_{I}{ }^{*} 5 \%$ & $\mu_{I}{ }^{*} 7 \%$ & $\mu_{I}{ }^{*} 1 \%$ \\
\hline
\end{tabular}

\section{RESULTS AND DISCUSSION}

The results obtained are for a three-phase fault at the MV busbar of the substation. In reference [2] the short circuit power obtained for deterministic values was of 299.28 MVA. In this way, probabilistic values were tested by MCS method with 1200 samplings, giving an error margin of 0.0475 (absolute value) over a confidence level of $99 \%$, as shown in the Fig. 3. MCS results were compared with those results obtained by interval arithmetic method.

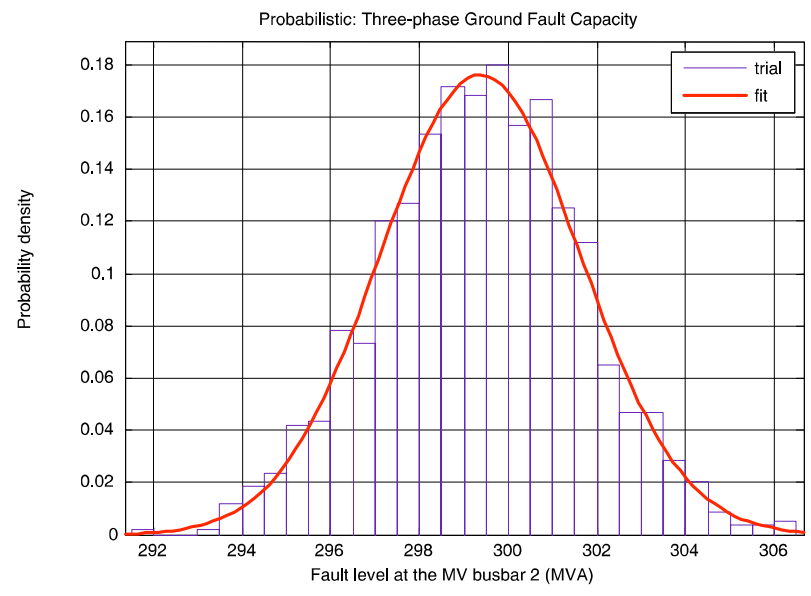

Fig. 3. Probabilistic three-phase ground fault at the MV busbar.

In the Fig. 3 results obtained from MCS for the calculation of the short circuit power for a three-phase fault at the MV bus bar vary between 292 and 306 MVA. This implies a fit by $\log$ likelihood test of a normal distribution of mean value of 299.369 MVA and standard deviation of 2.264 MVA Consequently, the short circuit power moves in the interval $299.369 \pm 2 * 2.264$ with a probability of $95.4 \%$.

The short-circuit power at the MV busbar 2 of the substation was evaluated through Interval Arithmetic, using $\alpha$-cuts of DG sources and network feeders. The corresponding results are depicted in the Fig. 4. Basic operations of interval arithmetic in short-circuit computations were implemented in Matlab, according to basic operations with $\alpha$-cuts of section III, subsection E using complex fuzzy numbers. However, F.N arithmetic can be also implemented using Interval Laboratory (IntLab) toolbox [13] available for Matlab.

In the Fig. 4 one can see that results obtained from IA for complex fuzzy numbers varies between 291 and 308 MVA, which is consistent to MCS results; possibilistic approach results by FN include a larger range of values of short-circuit capacity from those obtained by MCS method, due to IA uses extreme variable values (minimums and maximums) in their arithmetic operations. Instead, MCS takes the random trial of every variable and makes the calculus without exploring the lowest probability values, which means the worst values; hence it is necessary to launch a large number of trials for MCS, which could increase notably time resolution for larger power grids.

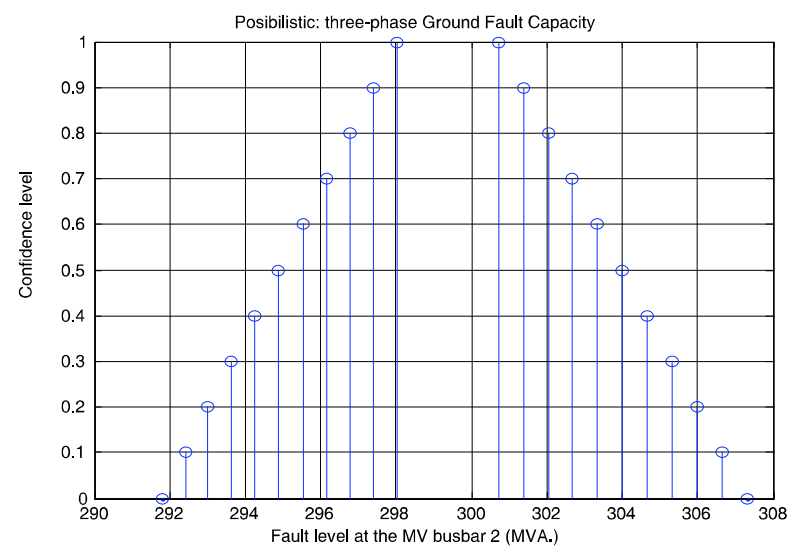

Fig. 4. Posibilistic three-phase ground fault at the MV busbar.

IA has better time performance compared to MCS. The time consumed by IA in three-phase fault was about $1 \mathrm{sec}$ for 11-cuts of membership functions, while for MCS results took $45 \mathrm{sec}$ and 1200 samplings. The simulation time saved by IA method was of $44 \mathrm{sec}$ compared to MCS. Therefore, IA can be a good method for larger power networks where the application of MCS method takes too much time. The fact that PPCP converts fuzzy numbers to probability density functions, allows to evaluate indirectly probabilities in terms of possibility distribution functions. It is important to notice fuzzy number must satisfy the conditions mentioned in section $\mathrm{C}$, in order to apply the PPCP.

IA of FN can be applied in any topology of power system in short-circuit calculus because calculus is based on arithmetical basic operations. Moreover, IA can be a new method in order to evaluate uncertainties, linked to the integration of renewable energy sources such as: wind power, photovoltaic, and others which have a stronger impact in power systems than conventional generation due to their variable generation.

\section{CONCLUSIONS}

IA offers a better and simple alternative for its implementation from MCS technique, which requires a large 
number of trials, or even from analytical method developed for early studies of probabilistic short-circuit. The concern about analytical technique, it requires the use of convolution techniques to obtain a final probability distribution, which can drive to numerical techniques very time consuming, to approach solutions of non-linear integral equations, not studied in this article. IA of FN is useful whenever it is necessary to deal, to evaluate and to solve problems with uncertainties

Short-circuit calculations can be done directly in phase domain [3] or by symmetric components theory; both methods are based on easy arithmetical operations that can be implemented by IA method. IA has been used in the past in power systems studies such as: radial power flow and reliability indices (ENS, SAIDI, and SAIFI), to deal with uncertainties problems, because their algorithms can be expressed in terms of several basic arithmetic operations. Hence, IA of FN can be applied to short-circuit computation in order to evaluate uncertainties of electrical variables. IA is limited to resolution of linear problems but it is an efficient way to evaluate uncertainties easily and efficiently.

On the basis of Zadeh's PPCP, probabilistic (MCS) and possibilistic (IA of FN) approaches of short-circuit calculation were tested in a distribution network, with four types of $\mathrm{DG}$ sources, studied in reference [2]. For the minimum value PPCP is valid, probabilistic and possibilistic algorithms were launched. The largest values of uncertainty of three-phase fault to ground were obtained by IA method. IA uses the deterministic values (minimums and maximums) from PODF in short-circuit calculus, instead of a random sampling as MCS. The fact that the time simulation saved with IA was inferior to the obtained from MCS is an advantage for the evaluation of uncertainties of larger power systems, for which the application of MCS would take very long time.

\section{REFERENCES}

[1] A. Balouktsis, D. Tsanakas and G. Vachtsevanos, "Probabilistic ShortCircuit Analysis by Monte Carlo Simulations and Analytical Methods," Power Systems, IEEE Transactions on, vol.1, no.3, pp.135-140, Aug. 1986

[2] T. Boutsika and S. A. Papathanassiou, "Short Circuit Calculations in Networks with Distributed Generation", Electric Power Systems Research, vol. 78, no. 7, pp. 1181-1191, July 2008.

[3] F. Castellanos and R. Dillah, "Short circuit analysis in the phase domain for distribution networks," Transmission and Distribution Conference and Exposition: Latin America, 2008 IEEE/PES , vol., no., pp.1-6, 13-15 Aug. 2008.

[4] P. Chen, Z. Chen and B. Bak-Jensen, "Probabilistic load flow: A review," Electric Utility Deregulation and Restructuring and Power Technologies, 2008. DRPT 2008. Third International Conference on, vol., no., pp.1586-1591, 6-9 April 2008.

[5] B. Das, "Radial distribution system power flow using interval arithmetic", Elect. Power Energy Syst., vol. 24, pp.827 - 836, 2002.

[6] G. L. Ford and K. D. Srivastava, "Probabilistic Short-Circuit Design of Substation Bus Systems", Proc. IEEE PES Winter Meeting, 1978.

[7] G. L. Ford and K. D. Srivastava, "The probabilistic approach to substation bus short-circuit approach to substation bus short-circuit design", Electric Power Systems Research, vol. 4, p.191, 1981.

[8] G. L. Ford and S. S. Sengupta, "Analytical methods for probabilistic short-circuit studies", Electric Power System Research, vol. 5, p.13, 1982.
[9] M. D. Germani and G. L. Ford, E. G. Neudorf, M. Vainberg, M. A. ElKady, R. W. D. Ganton, "Probabilistic Short-Circuit Uprating of Station Strain Bus System Overview and Application," Power Engineering Review, IEEE, vol.PER-6, no.7, pp.43-44, July 1986.

[10] D. G. Havard, C. J. Pon, H. A. Ewing, G. D. Dumol and A. C. Wong, "Probabilistic Short-Circuit Uprating of Station Strain Bus System Mechanical Aspects," Power Delivery, IEEE Transactions on, vol.1, no.3, pp.104-110, July 1986.

[11] D. L. Mon and C. H. Cheng, "Fuzzy system reliability analysis by interval of confidence," Fuzzy Sets Systems., vol.56. pp. 2-35, 1993.

[12] N. Ramani, L. Wang, W. H. Tanaka and F. X. Macedo, "Probabilistic Short-Circuit Uprating of Station Strain Bus System - Reliability and Operating Considerations," Power Delivery, IEEE Transactions on , vol.1, no.4, pp.137-141, Oct. 1986.

[13] S. M. Rump, "INTLAB-INTerval LABoratory", In Tibor Csendes, editor, Developments in Reliable Computing, pp. 77-105. Kluwer, Dordrecht, Netherlands, 1999.

[14] M. Vainberg, M. A. El-Kady, G. L. Ford, R. W. D. Ganton, M. D. Germani and E. G. Neudorf, "Probabilistic Short-Circuit Uprating of Station Strain Bus System - Probabilistic Formulation," Power Delivery, IEEE Transactions on, vol.1, no.4, pp.129-136, Oct. 1986.

[15] Vestas Advanced Grid Option 3-V52-850 kW, V66-1.75 MW, V80-2.0 MW, Technical description, 2003.

[16] L. A. Zadeh, "Fuzzy sets as a basis for a theory of possibility", Fuzzy Sets and Systems, No.1, pp.3-28, 1978.

\section{BIOGRAPHIES}

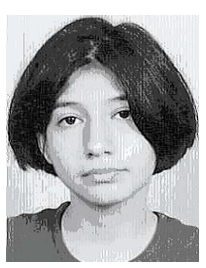

Wendy Carolina Briceño Vicente graduated as Electrical Engineer from the Engineering Faculty in the Universidad Central de Venezuela (UCV), Venezuela, in 2006. She obtained her Master at the Grenoble Institute of Technology (Grenoble INP), France, in 2009. Presently she is preparing a Ph.D. thesis in Grenoble Electrical Engineering laboratory (G2Elab).

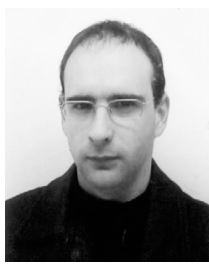

Raphael Caire (M'04) received his Diplômed'Etudes Approfondies (DEA) and Doctorat degrees from the Institut National Polytechnique de Grenoble (INPG) in 2000 and 2004. He had been working in Power Electronic field, in USA at the Center of Power Electronic System (CPES) in 2000 and within several EDF research centers in Germany and in France from 2004 to 2006 . He is now associate professor at Grenoble Institute of Technology (Grenoble-INP) at the Ecole Nationale Supérieure d'Ingénieurs Electriciens de Grenoble (ENSE3) in the Grenoble Electrical Engineering laboratory (G2Elab). His research is centered on the impacts, production control of dispersed generation on distribution system and critical infrastructures.

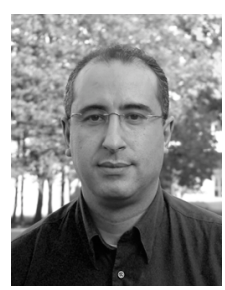

Nouredine Hadjsaid (SM'05) received his Diplôme d'Etudes Approfondies (DEA) and Doctorat de l'INPG degrees from the Institut National Polytechnique de Grenoble (INPG) in 1988 and 1992. From 1988 to 1993, he served as a research and teaching assistant at the Ecole Nationale Supérieure d'Ingénieurs Electriciens de Grenoble (ENSIEG) and at the Laboratory d'Electrotechnique de Grenoble (LEG). $\mathrm{He}$ is now a full time professor professor at Grenoble INP at the Ecole d'Ingénieurs pour l'Energie, l'Eau et l'Environnement de Grenoble (ENSE3) in the Grenoble Electrical Engineering laboratory (G2Elab). His research interests are power system operation and security. Since 1992, he has been involved as a scientific director for more than 20 industrial and European projects in the power energy sector and critical infrastructures. These projects concern in particular power system security, new technologies to enhance power system control and monitoring, optimization of distribution systems, distributed generation, ancillary services and planning under deregulation, Information and Communication for Energy for example. 